\title{
Energy expenditure, recovery oxygen consumption, and substrate oxidation during and after body weight resistance exercise with slow movement compared to treadmill walking
}

\author{
T Nakagata ${ }^{1,2}$, Y Yamada $^{2}$, H Naito ${ }^{1}$ \\ ${ }^{1}$ Graduate School of Health and Sports Science, Juntendo University, Chiba, Japan \\ ${ }^{2}$ National Institute of Health and Nutrition, National Institute of Biomedical Innovation, Health and Nutrition, \\ Tokyo, Japan
}

Received: April 9, 2018

Accepted: November 9, 2018

\begin{abstract}
The benefit of body weight resistance exercise with slow movement (BWRE-slow) for muscle function is welldocumented, but not for energy metabolism. We aimed to examine physiological responses [e.g., energy expenditure (EE), respiratory exchange ratio (RER), and blood lactate (La)] during and after BWRE-slow compared to EE-matched treadmill walking (TW). Eight healthy young men $(23.4 \pm 1.8$ years old, $171.2 \pm 6.2 \mathrm{~cm}, 63.0 \pm 4.8 \mathrm{~kg})$ performed squat, push-up, lunge, heel-raise, hip-lift, and crunch exercises with BWRE-slow modality. Both the concentric and eccentric phases were set to $3 \mathrm{~s}$. A total of three sets ( 10 repetitions) with $30 \mathrm{~s}$ rest between sets were performed for each exercise (26.5 $\mathrm{min}$ ). On another day, subjects walked on a treadmill for $26.5 \mathrm{~min}$ during which EE during exercise was matched to that of BWRE-slow with the researcher controlling the treadmill speed manually. The time course changes of EE and RER were measured. The EE during exercise for BWRE-slow (92.6 $\pm 16.0 \mathrm{kcal}$ for $26.5 \mathrm{~min})$ was not significantly different from the EE during exercise for TW $(95.5 \pm 14.1 \mathrm{kcal}, p=0.36)$. BWRE-slow elicited greater recovery EE $(40.55 \pm 3.88 \mathrm{kcal}$ for $30 \mathrm{~min})$ than TW $(37.61 \pm 3.19 \mathrm{kcal}, p=0.029)$. RER was significantly higher in BWRE-slow during and 0-5 min after exercise, but became significantly lower during 25-30 min after exercise, suggesting greater lipid oxidation was induced about $30 \mathrm{~min}$ after exercise in BWRE-slow compared to TW. We also indicated that BWRE-slow has 3.1 metabolic equivalents in average, which is categorized as moderate-intensity physical activity.
\end{abstract}

Keywords: energy metabolism, FAT oxidation, $\mathrm{CHO}$ oxidation, respiratory exchange ratio, respiratory quotient

\section{Introduction}

It is well-documented that daily physical activity (PA) or exercise (Ex) prevents lifestylerelated diseases, such as metabolic syndrome, type-II diabetes, cardiovascular disease, several types of cancer, and/or age-related loss of skeletal muscle or physical function (15). Walking is the most popular PA or Ex in a wide range of age groups in Japan, with $38.7 \%$ of Japanese people who reported that they engaged in Ex in the past year undertaking

\footnotetext{
Corresponding author: Takashi Nakagata, PhD

Graduate School of Health and Sports Science, Juntendo University Hiraka-gakuendai

1-1, Inzai, Chiba 270-1695, Japan

Phone: +81 47390 1001; Fax: +81 47698 1030; E-mail: tanakaga@juntendo.ac.jp

Current address: Takashi Nakagata

Sportology Center, Juntendo University Graduate School of Medicine

2-1-1, Hongo, Bunkyo-ku, Tokyo 113-8421, Japan

Phone: +81338133111
} 
walking, which was followed by conditioning Exs or light-intensity rhythmical gymnastics (15.0\%), resistance exercise (RE; 14\%), jogging/running (10.4\%), and cycling (8.8\%) (18). The average metabolic equivalent (MET) of walking for leisure is 3.5, 3.0 for walking at a usual speed $(4.0 \mathrm{~km} / \mathrm{h})$, and 4.3 for walking at a brisk speed $(5.6 \mathrm{~km} / \mathrm{h})(1)$. One benefit of walking is the regulation of body weight by increasing energy expenditure (EE) and lipid (FAT) oxidation. PA guidelines also recommend muscle-strengthening activity (i.e., RE) for 2 or more days per week in addition to aerobic activity to prevent age-related loss of muscle and bone tissue and physical function (43). Recently, Kamada et al. (19) reported that $\leq 145 \mathrm{~min} /$ week of RE in older women has beneficial effects on all cause and cardiovascular disease.

Usually, RE is conducted using specific machines, including free weights or equipment with high-load intensity ( $\sim 60 \%-80 \%$ of one repetition maximum) (2). Recently, as alternative to these RE, methods such as low-load and high-repetition RE $(10,25,26)$ or low-intensity RE and tonic force generation with slow movement $(33,34)$ have been investigated, and researchers have found these methods to be effective. However, even these alternative methods generally need machines and free weights, so access to these types of RE is still limited. In contrast, body weight resistance exercise (BWRE) does not need any equipment and can be performed in any setting within a small space. Previous studies have reported that BWRE is effective in improving muscle strength in healthy elderly people $(14,28,45)$. The main limitation of BWRE is that the Ex is limited to low- to middle-load training, so that the effect of BWRE on muscle strength is weaker than that of the traditional RE.

To overcome the limitation, Watanabe et al. (39) examined BWRE with tonic force generation during slow movement (BWRE-slow) in older adults, and found that this RE improved muscle strength. Tsuzuku et al. (37) also found that BWRE-slow improved muscle strength in the elderly, accompanied by muscle hypertrophy. BWRE-slow can be conducted easily in any setting within a small space and attenuate hypertension during RE. However, to the best of our knowledge, the beneficial effect of BWRE-slow for energy metabolism is not well examined.

Previous studies have reported that mean EEs of traditional RE or circuit RE using freeweights or machines with high-loads ranging between 5 and $10 \mathrm{kcal} / \mathrm{min}(4,5,7,21)$, and the energetic profile of RE are different in mild aerobic Ex such as walking or jogging (20). It is well-known that high-intensity $\mathrm{RE}$ depends on carbohydrate $(\mathrm{CHO})$ resources more than the FAT resources during Ex. However, because of the depletion of $\mathrm{CHO}$ in the contracted muscle cells by high-intensity RE, the FAT oxidation, when monitored by indirect calorimetry or other methods, is enhanced $30 \mathrm{~min}$ or $1 \mathrm{~h}$ after Ex to spare $\mathrm{CHO}$, and facilitates subsequent muscle glycogen restoration using $\beta$-oxidation system (23).

Nakagata et al. (27) recently indicated that the intensity (METs) and EE of BWRE-slow are much smaller than those of traditional RE using free-weights or machines (1.8-3.7 METs). This fact suggests that the BWRE-slow is equivalent to normal speed walking in terms of EE. However, because the Ex modality is quite different between BWRE-slow and walking, other physiological responses, such as recovery oxygen consumption (ROC), and substrate oxidation during and after Ex may be different between BWRE-slow and EE-matched walking, although no previous studies examined this to our best knowledge.

$\mathrm{RE}$ is an intermittent Ex including bouts of Ex and short-recovery intervals. On the contrary, walking is a continuous Ex. Two previous studies compared the physiological response of traditional RE using free-weights and machines with exercise energy expenditure (Ex EE)-matched treadmill walking (TW) or jogging $(8,11)$. Comparison of physiological 
responses including ROC and substrate oxidation during and after Ex of RE against Ex EE-matched TW or jogging gives a better understanding of the characteristics of energy metabolism of RE. In particular, because the intensity of BWRE-slow is light-to-moderate, we assumed this method is useful to detect subtle differences of energy metabolism between BWRE-slow and normal speed walking. We hypothesized that ROC and substrate oxidation during recovery of BWRE-slow were still different from TW, although the intensity of BWRE-slow is much lower than that of the traditional RE using free-weights and machines.

The purpose of this study was to compare the physiological responses [i.e., EE, respiratory exchange ratio (RER), and blood lactate (La), heart rate (HR), ROC, and substrate oxidation] of BWRE-slow compared to Ex EE-matched TW.

\section{Materials and Methods}

\section{Participants}

Nine healthy young adults aged 22-27 years participated in the study. The subjects took the annual health examination of the university and had no problem with blood pressure and electrocardiogram, and no previous history of established cardiovascular, pulmonary, and neurological diseases. However, we stopped the investigation in one subject, because he complained about sickness on the day of measurement; therefore, this study included eight subjects $(23.4 \pm 1.8$ years old, $171.2 \pm 6.2 \mathrm{~cm}, 63.0 \pm 4.8 \mathrm{~kg}$; Table I). The subjects had regular Ex habits (1-3 days per week); they were familiarized with the BWRE. Prior to the study, all subjects provided written consent to participate after receiving information on the procedures and purpose of the study. All subjects successfully conducted maximal oxygen consumption test without any symptoms.

The sample size was calculated with GPower 3.1.3 (Dusseldorf, Germany) based on assumption of the clinical significant differences in ROC between BWRE and TW a priori as effect size $d=1.2$ of two dependent means (matched pairs), with we set $\alpha$ error prob $=0.05$ and power $(1-\beta)=0.8$. The required total sample size was estimated to be $n=8$.

\section{Experimental design}

Subjects performed a BWRE-slow session before a TW session. This was because we needed to match the EE during TW to that of BWRE-slow. All measurements were carried out in a laboratory where the temperature and humidity of the internal atmosphere was adjusted to

Table I. Subject characteristics $(n=8)$

\begin{tabular}{|l|c|c|}
\hline Variables & Mean \pm SD & Range \\
\hline Age (years) & $23.4 \pm 1.8$ & $22.0-27.0$ \\
\hline BMI & $21.5 \pm 1.2$ & $19.1-23.3$ \\
\hline Body fat (\%) & $11.9 \pm 2.9$ & $8.6-17.7$ \\
\hline$\dot{V} \mathrm{O}_{2 \max }$ & $55.4 \pm 6.2$ & $46.0-63.9$ \\
\hline $\mathrm{HR}_{\max }$ & $197.0 \pm 8.1$ & $192-214$ \\
\hline
\end{tabular}

$\mathrm{SD}$ : standard deviation; BMI: body mass index; $\dot{V O}_{2 \max }$ : maximum oxygen uptake; $\mathrm{HR}_{\max }$ : heart rate maximum 


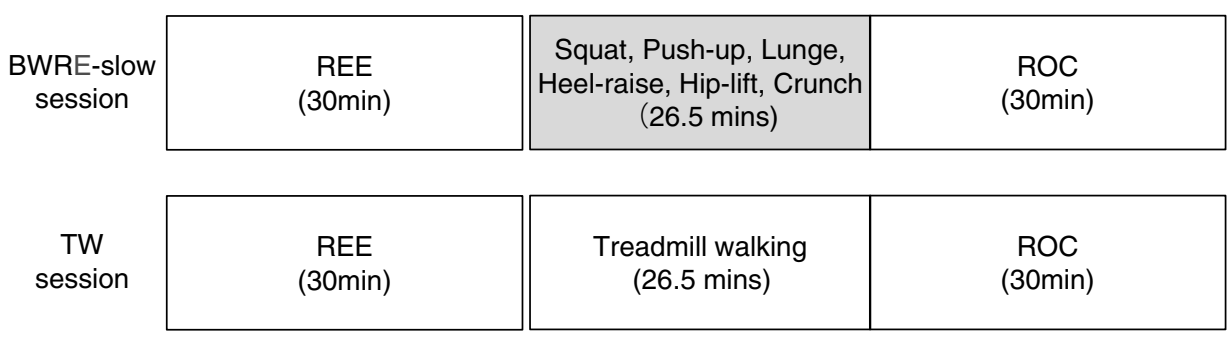

Fig. 1. Experimental protocol. BWRE-slow: body weight resistance exercise with slow movement; TW: treadmill walking; REE: resting energy expenditure; ROC: recovery oxidation compensation

$20{ }^{\circ} \mathrm{C}$ and $50 \%$. All subjects completed both experiments on two separate days between October 2016 and March 2017.

The experimental schedule set is shown in Fig. 1. The subjects in this study refrained from any strenuous PA from the day before the experiment. Subjects had an ad libitum lunch before 1 p.m. and came to the laboratory at $6 \mathrm{p} . \mathrm{m}$. without water restriction. A meal ( $\sim 15 \%$ protein, $\sim 25 \%$ fat, and $\sim 60 \%$ CHO) was provided at 7 p.m. to all subjects in both BWRE-slow and TW sessions. Calories were calculated for each subject based on their body weight. After one night in the laboratory (sleep between 11 p.m. and 7 a.m.), both sessions were completed.

The resting energy expenditure (REE) was measured in both the BWRE-slow and TW sessions using an indirect calorimeter (AE-300s, Minato Medical Science Co., Ltd., Osaka, Japan), while sitting on a chair, maintaining a resting position for $30 \mathrm{~min}$ with a face mask attached. After measurement of REE, subjects carried out a BWRE-slow or TW session. Immediately after Ex, the subjects sat on a chair quietly with a face mask attached and rested in this position for $30 \mathrm{~min}$.

\section{RE protocol}

The BWRE-slow session consisted of the following six Exs using body weight: squat, push-up, lunge, heel-raise, hip-lift, and crunch. All subjects performed the BWRE-slow in the same order. Details of the BWRE-slow are described in our previous study (27). It is recommended that RE programs order the performance of Exs to optimize the preservation of Ex intensity (large before small muscle group Exs, multiple-joint Exs before single-joint Exs, and rotation of upper and lower body), so all subjects started with squats and finished with crunches. Both the concentric and eccentric phases were set to $3 \mathrm{~s}$ ( $6 \mathrm{~s}$ with one iteration), and the subjects adjusted the rhythm to the sound of a metronome. A total of 10 repetitions were defined as one set ( $1 \mathrm{~min}$ in total), rest between the sets was $30 \mathrm{~s}$, and a total of three sets were performed. This experiment lasted for a total of $26.5 \mathrm{~min}$.

\section{TW protocol}

All subjects performed a TW session on a motorized treadmill for $26.5 \mathrm{~min}$ on another day; the sessions were separated by a minimum of 2 days. Entire experimental schedule to spend the day before the TW was set in the same way as for the BWRE-slow. To facilitate the matching of EE during Ex, the BWRE-slow always preceded the TW. Initial treadmill speed was set to $60-70 \mathrm{~m} / \mathrm{min}$ for $4 \mathrm{~min}$ at zero grade, and then the speed was adjusted in order to match the EE of the average BWRE-slow session in every 2 min. 
$\dot{V} \mathrm{O}_{2 \max }$ measurement

Maximal oxygen consumption $\left(\mathrm{VO}_{2 \max }\right)$ was estimated from a graded maximal Ex test (GXT) using the treadmill. The GXT started at $100 \mathrm{~m} / \mathrm{min}$ for $2 \mathrm{~min}$, and then increased to $20 \mathrm{~m} / \mathrm{min}$ every $1 \mathrm{~min}$ until exhaustion. HR was measured during GXT every $1 \mathrm{~min}$, and earlobe blood samples were obtained immediately after GXT to measure the La levels. We set the following criteria before the GXT to determine the $V \mathrm{O}_{2 \max }$; (1) the change in $V \mathrm{O}_{2}$ of $2.1 \mathrm{ml} \cdot \mathrm{kg}^{-1} \cdot \mathrm{min}^{-1}$ between two consecutive stages was defined as the so-called "plateau or leveling off'. during GXT (35), and the highest maximum value was defined as the $V \mathrm{O}_{2 \max }$ (2). If the $V \mathrm{O}_{2}$ plateau or leveling off was not attained, more than two of the following needed to be met as secondary criteria: (1) maximum $\mathrm{HR}\left(\mathrm{HR}_{\max }\right) \leq 10$ beats $/ \mathrm{min}$ of the age-predicted (age: 220 years old) maximum, (2) $\mathrm{La} \geq 8 \mathrm{mM} / \mathrm{L}$, and (3) RER $\geq 1.15$ (17). Six subjects achieved primary criteria, and other two subjects met the secondary criteria during GXT; therefore, all subjects met the criteria of $V \mathrm{O}_{2 \max }$.

\section{Anthropometry and body composition}

The height of subjects was measured to the closest $0.1 \mathrm{~cm}$ using an analog height meter. Body weight was measured and body fat percentage was estimated using the impedance method (Inbody 730, Biospace, Tokyo, Japan) after overnight fasting (12 h) and at least $30 \mathrm{~min}$ after getting up in the morning before Ex. Participants were instructed to empty their bladder before the measurement. They were evaluated in their underwear in a standing position, and were asked to stand barefoot on toe-and-heel electrodes and to hold the handgrips with arms hanging down a few centimeters from the hip (44).

\section{Indirect calorimetry measurement}

Respiratory gas measurement using indirect calorimetry and a face mask was carried out in our laboratory as previously described (27). Prior to the start of the experiment, the flow rate sensor was calibrated using a 2-L syringe, and the concentration sensor was calibrated for a gas mixture with known concentrations $\left(\mathrm{O}_{2} 14.98 \%, \mathrm{CO}_{2} 4.99 \%, \mathrm{~N}_{2}\right.$ balance; $\mathrm{O}_{2} 20.73 \%$, $\mathrm{N}_{2}$ balance). All data were processed in every $30 \mathrm{~s}$ and the oxygen uptake $\left(V \mathrm{O}_{2}\right)$ and carbon dioxide production $\left(V \mathrm{CO}_{2}\right)$ were measured. $\mathrm{EE}(\mathrm{kcal} / \mathrm{min})$ was calculated from the Weir's (40) equation. RER was obtained as $\dot{V} \mathrm{CO}_{2} / V \mathrm{O}_{2}$. Fat and $\mathrm{CHO}$ oxidation rate were estimated from Frayn's (13) equations. We defined a MET as the average value of $\mathrm{VO}_{2}$ during the last 10 min of REE in each individual under sitting and resting conditions for $30 \mathrm{~min}$. After the Exs, ROC $(9,32)$ was measured for $30 \mathrm{~min}$ under sitting and resting conditions.

\section{$H R$ and rating of perceived exertion (RPE)}

HR was recorded for the duration of the experiment using an electrocardiogram device (Fukuda Electronics Co., Ltd., Tokyo, Japan). Three beats were recorded $15 \mathrm{~s}$ before the end of each set, and the average value of a total of nine was taken as the HR for each Ex. RPEs were recorded using a Borg scale (6-20 steps) after the Ex.

\section{La concentration}

Blood samples $(20 \mu \mathrm{l})$ were taken from the earlobe using a capillary tube (17) before, immediately, after (0), 5, 10, 20, and 30 min after BWRE-slow and TW Exs. La concentrations were analyzed using a Biosen S-Line device (EKF Diagnostik, Barleban, Germany). 
Statistical analyses

Microsoft Office Excel 2017 and PASW Statistics version 20.0 (SPSS, IBM Inc., IBM Corp., Armonk, NY, USA) were used for data processing and statistical analyses, respectively. All variable results were presented as mean \pm standard deviation. To examine the main effect (Ex mode and Time) and interaction (Ex mode $\times$ Time), two-way repeated analysis of variance (ANOVA) was conducted for each variable. One-way repeated ANOVA was conducted to examine the main effect for each variable in each Ex mode separately, if the significant interaction was observed. A paired $t$-test was conducted to determine significant differences between BWRE-slow and TW. The statistical significance level was set at 0.05 .

\section{Results}

Pre-Ex resting data for mean EE, RER, HR, and La were not significantly different on the testing days (Table II). Mean and total EE during BWRE-slow and TW were not significantly different. We could control the EE during both Exs and the mean TW speed was $66.8 \pm 7.8 \mathrm{~m} / \mathrm{min}$. In addition, RER, HR, and RPE during Ex were significantly higher for BWRE-slow compared to TW (Table II). Furthermore, La during recovery after Ex in BWRE was significantly greater than TW $(3.5 \pm 1.0$ vs. $0.9 \pm 0.2 \mathrm{mM} / \mathrm{L}, p<0.001)$.

Table II. Physiological responses before, during, and after exercise

\begin{tabular}{|c|c|c|c|}
\hline Variables & BWRE-slow session & TW session & $p$ value \\
\hline \multicolumn{4}{|c|}{ Before exercise (rest) } \\
\hline $\mathrm{EE}(\mathrm{kcal} / \mathrm{min})$ & $1.2 \pm 0.1$ & $1.1 \pm 0.1$ & 0.28 \\
\hline RER & $0.86 \pm 0.03$ & $0.88 \pm 0.03$ & 0.15 \\
\hline HR (bpm) & $66.8 \pm 11.4$ & $66.8 \pm 9.6$ & 1.00 \\
\hline $\mathrm{La}(\mathrm{mM} / \mathrm{L})$ & $0.9 \pm 0.2$ & $0.9 \pm 0.2$ & 0.90 \\
\hline \multicolumn{4}{|c|}{ During exercise $(\mathrm{Ex})$} \\
\hline $\mathrm{EE}(\mathrm{kcal} / \mathrm{min})$ & $3.5 \pm 0.6$ & $3.6 \pm 0.5$ & 0.36 \\
\hline METs & $3.1 \pm 0.3$ & $3.2 \pm 0.4$ & 0.22 \\
\hline RER & $0.98 \pm 0.03$ & $0.84 \pm 0.02$ & $<0.001 *$ \\
\hline HR (bpm) & $98.8 \pm 14.0$ & $87.2 \pm 10.6$ & $<0.001 *$ \\
\hline $\mathrm{La}(\mathrm{mM} / \mathrm{L})$ & $3.5 \pm 1.0$ & $0.9 \pm 0.2$ & $<0.001 *$ \\
\hline RPE & $13.5 \pm 2.3$ & $9.0 \pm 2.0$ & $<0.001 *$ \\
\hline \multicolumn{4}{|c|}{ After exercise for $30 \mathrm{~min}$} \\
\hline $\mathrm{EE}$ (kcal) & $40.6 \pm 3.9$ & $37.6 \pm 3.2$ & $0.029 *$ \\
\hline
\end{tabular}

BWRE-slow: body weight resistance exercise with slow movement; TW: treadmill walking; EE: energy expenditure; RER: respiratory exchange ratio; Ex: exercise; METs: metabolic equivalents; HR: heart rate; La: blood lactate; RPE: rating of perceived exertion.

*Statistically significant 
A

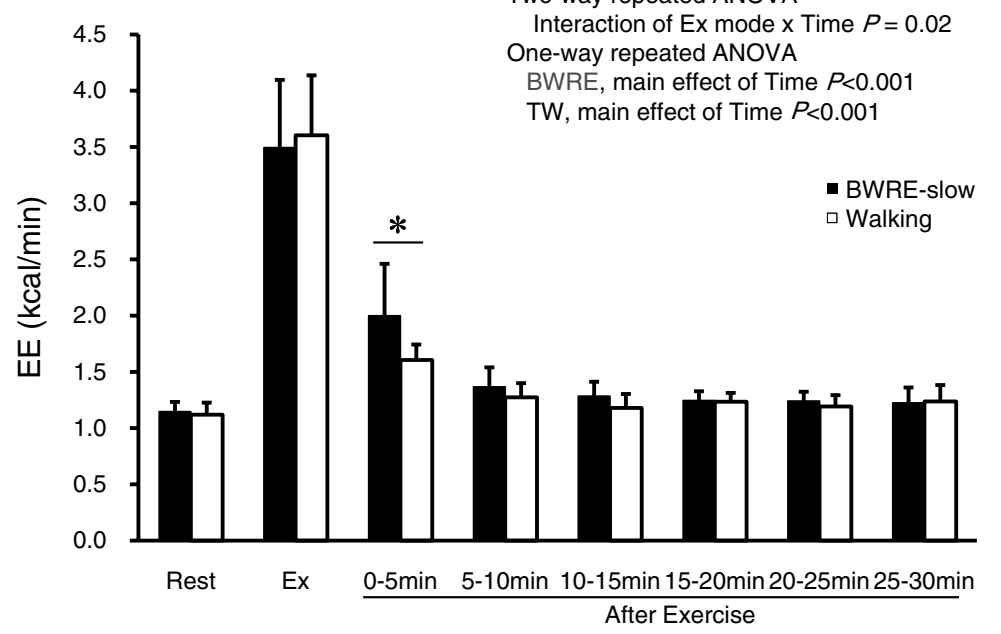

B

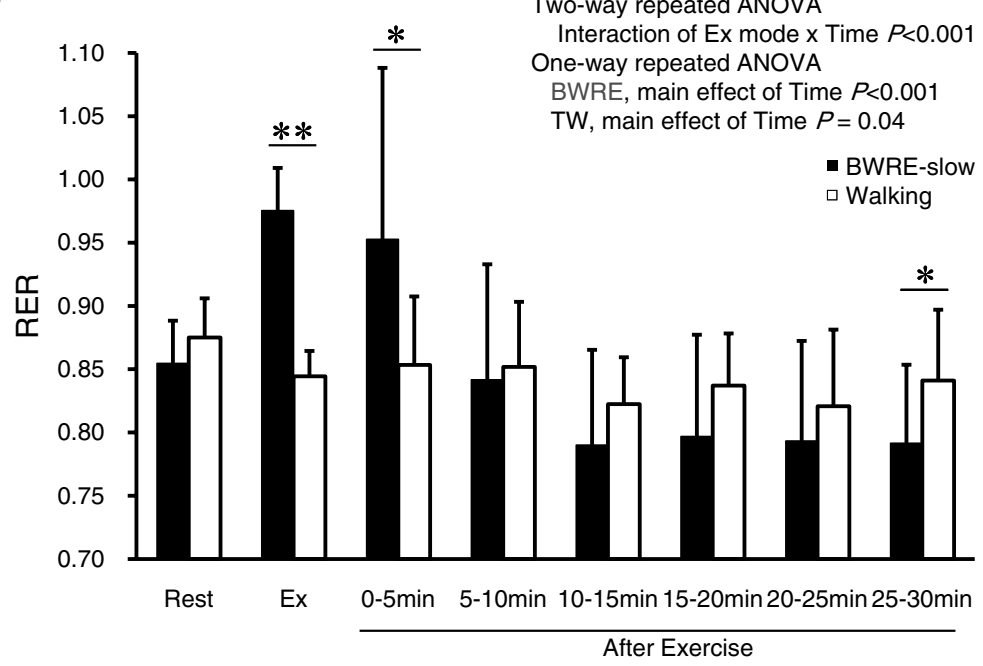

Fig. 2. (A) Energy expenditure (EE) during rest, Ex, and after Ex for BWRE-slow with slow movement and TW with matched EE. There is no significant difference in Ex EE for BWRE-slow and TW. Two-way repeated ANOVA shows significant interaction between Ex mode $\times$ Time and BWRE-slow EE 0-5 min after Ex is significantly higher than after TW $(p=0.04)$. (B) Respiratory exchange ratio (RER) during rest, Ex, and after Ex for BWRE-slow and TW with matched EE. Two-way repeated ANOVA shows significant interaction between Ex mode $\times$ Time. The RER during Ex and immediately after Ex (0-5 min) for BWRE-slow is significantly higher than for TW. In contrast, RER 25-30 min after Ex for BWRE-slow is significantly lower than TW. ${ }^{*} p<0.05,{ }^{*} p<0.01$, significant difference between Ex modes

Figure $2 \mathrm{~A}$ shows the mean $\mathrm{EE}(\mathrm{kcal} / \mathrm{min})$ at pre-Ex, during Ex, and post-Ex. Although EE during Ex was not significantly different for the Exs, EE for BWRE-slow was significantly higher than EE for TW immediately after Ex (0-5 min) only. The post-Ex EE for both Exs was significantly higher than at rest and 0-5 and 5-10 min post-Ex. 
A

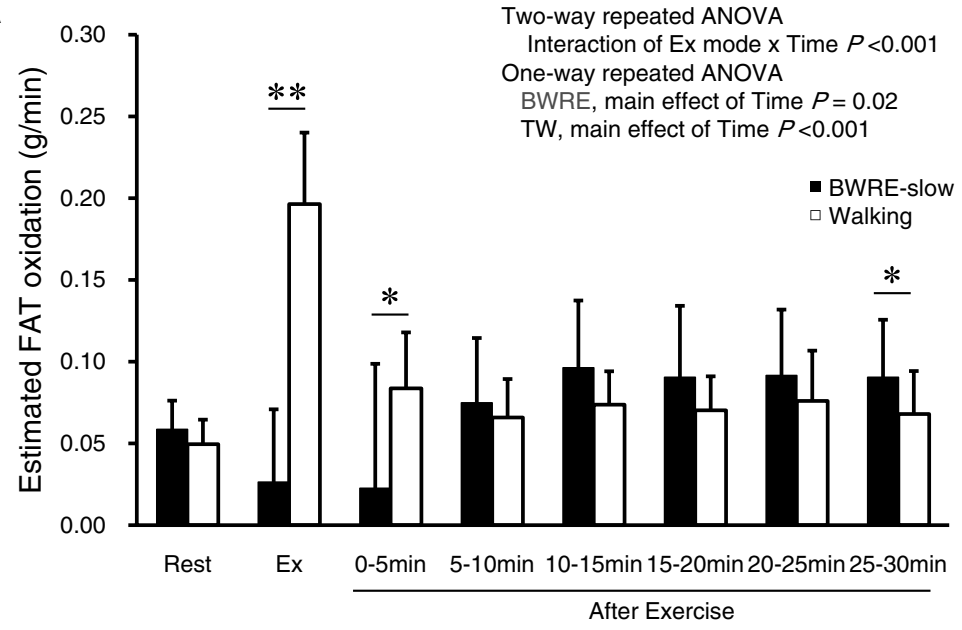

B

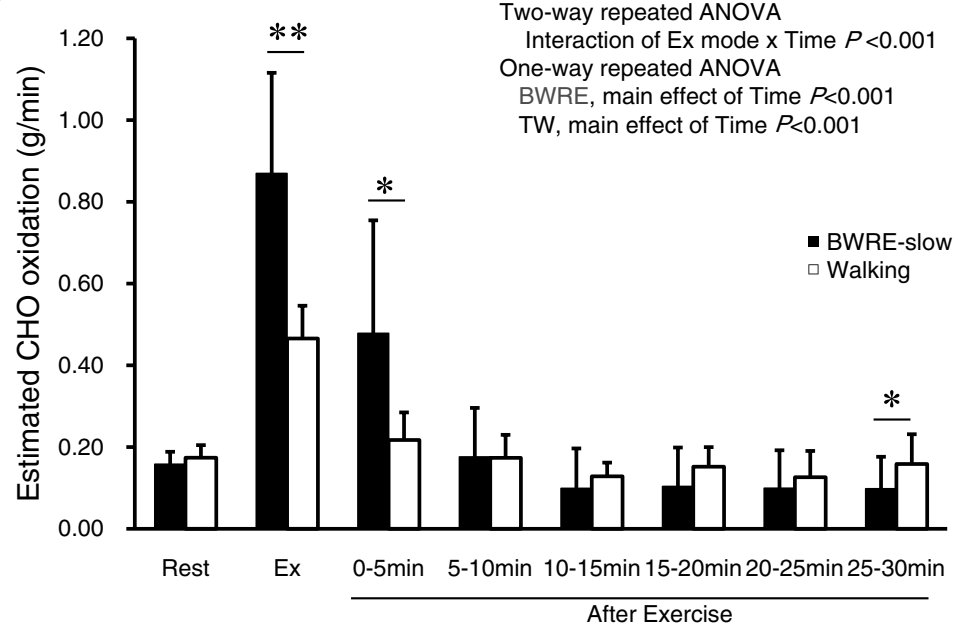

Fig. 3. (A) Estimated FAT oxidization during rest, Ex, and after Ex for BWRE-slow and TW with matched EE. Two-way repeated ANOVA shows a significant interaction between Ex mode $\times$ Time, and the FAT oxidization for BWRE-slow is significantly lower than for TW during Ex and immediately after Ex (0-5 min). The FAT oxidization for BWRE-slow 25-30 min after Ex is higher than that of TW. (B) Estimated carbohydrate (CHO) oxidization during rest, Ex, and after Ex for BWRE-slow and TW with matched EE. Two-way repeated ANOVA shows significant interaction between Ex mode $\times$ Time and the $\mathrm{CHO}$ oxidization for BWRE-slow is significantly higher than for TW during Ex and immediately after Ex (0-5 min). The CHO oxidization for BWRE-slow 25-30 min after Ex is lower than for TW. Note that the FAT and $\mathrm{CHO}$ oxidations were estimated using indirect calorimetry based $\dot{V} \mathrm{O}_{2}$ and $\dot{V} \mathrm{CO}_{2}$, so that the actual oxidation time course must be different from this figure. ${ }^{*} p<0.05,{ }^{*} p<0.01$, significant difference between Ex modes

Figure 2B shows mean RER at pre-Ex, during Ex, and post-Ex. During both Ex and immediately post-Ex (0-5 min), RERs were higher for BWRE-slow than TW. In addition, RER gradually decreased for BWRE-slow during post-Ex and was lower 25-30 min post-Ex compared to TW $(p=0.02)$. 
Figure 3A,B shows estimated FAT and estimated $\mathrm{CHO}$ oxidation rate using indirect calorimetry during Ex and post-Ex. During Ex, $\mathrm{CHO}$ was oxidized mainly in BWRE-slow, whereas FAT was mainly oxidized in TW. FAT oxidation during post-Ex for BWRE-slow increased after Ex, and there was a significant difference at 25-30 min post-Ex. Similarly, CHO oxidation for BWRE-slow was significantly lower than for TW at 25-30 min post-Ex.

\section{Discussion}

In this study, we examined the EE and ROC during BWRE-slow and walking, with EEs matched for the two Exs using indirect calorimetry and La measurement. The mean EE for BWRE-slow was $3.5 \pm 0.6 \mathrm{kcal} / \mathrm{min}$ and $92.6 \pm 16.0 \mathrm{kcal}$ across the entire 26.5 -min BWRE-slow session. The Center of Disease Control and Prevention, USA and American College of Sport Medicine PA guideline (38) and Compendium of Physical Activities (1) defined 3.0-5.9 METs as moderate intensity, <1.5 METs as sedentary, 1.6-2.9 METs as light intensity, and >6.0 METs as vigorous intensity activity. BWRE-slow had $3.1 \pm 0.3$ METs in average (range: 2.7-3.7 METs that varies from low to moderate among individuals). We found that intensity is equivalent to normal walking with $\sim 4 \mathrm{~km} / \mathrm{h}$ speed.

Previous studies have reported mean EEs of RE using free-weights or machines with high-loads ranging between 5 and $10 \mathrm{kcal} / \mathrm{min}(5-8 \mathrm{METs})(1,4,7)$. This study demonstrated mean EE and METs for BWRE-slow of $3.5 \pm 0.6 \mathrm{kcal} / \mathrm{min}$ and $3.1 \pm 0.3 \mathrm{METs}$, respectively, which were lower than in previous studies. The difference in EE between this study and previous studies could be a result of differences in the load (free-weight/machine vs. body weight), so the current results are not surprising. In addition, traditional high-load RE increases HR (up to $\left.140-160 \mathrm{bpm}, 80 \% \mathrm{HR}_{\max }\right)(4,41)$, but the HR for BWRE-slow was only $98.8 \pm 14.0 \mathrm{bpm}$ (approximately $50 \% \mathrm{HR}_{\max }$ ). Therefore, BWRE-slow is considered low-to-moderate intensity at least for healthy young men.

The RE with free-weights or machines results in an $V \mathrm{O}_{2}$ elevation above resting levels after a single Ex, such as ROC $(6,29)$. For example, Binzen et al. (6) reported that a high-load and high-volume RE protocol (10 Exs $\times 3$ sets, 70\%-80\% 1RM, total $45 \mathrm{~min}$ ) induced ROC ( $2 \mathrm{~h}$ ) that was $18.6 \%$ higher compared to a sitting control condition (RE: $167 \pm 12 \mathrm{kcal}$ vs. control: $136 \pm 2 \mathrm{kcal}$ ). As shown in Fig. 2A, EE after BWRE-slow was significantly higher than the resting levels at $0-5,5-10$, and 15-20 min, but returned to resting levels at 20-25 and 25-30 min post-Ex, and the total EE (gross) for 30 min was $40.6 \pm 3.9 \mathrm{kcal}$ (Table III). Therefore, considering the EE and ROC, the total EE during BWRE-slow was moderate.

A unique aspect of this study was that all subjects performed TW trials with manually controlling their walking speeds, matching the Ex EE of BWRE-slow in each subject. In literature, Burleson et al. (11) and Braun et al. (8) investigated physiological responses after $\mathrm{RE}$ and TW with matched total EE and time during Ex. We adjusted the experimental design to these previous studies, so that we could compare the current result to the previous results. In the previous and the present studies, BWRE-slow was performed on the first experimental day for each subject, and then the matched TW session was conducted on another day. There were no differences in EE and HR before Ex, and EE during Ex in this study $(3.5 \pm 0.6 \mathrm{kcal} / \mathrm{min}, 3.6 \pm 0.5 \mathrm{kcal} / \mathrm{min}, 92.6 \pm 16.0,95.5 \pm 14.1$; Table III $)$, as well as the previous studies. Burleson et al. (11) and Braun et al. (8) reported that RE resulted in a 30-min total ROC that was approximately $50 \%$ and $17 \%$ higher than the treadmill Ex, respectively. 
Table III. Studies examining recovery oxygen consumption (ROC) for resistance training and treadmill locomotion with matched EE during Ex

\begin{tabular}{|c|c|c|c|}
\hline Study & Burleson et al. (1998) & Braun et al. (2005) & Current study \\
\hline \multicolumn{4}{|c|}{ Physiological characteristics of subjects } \\
\hline $\begin{array}{l}\text { Number of } \\
\text { subjects }\end{array}$ & 15 & 8 & 8 \\
\hline Sex & Men & Women (pre-menopausal) & Men \\
\hline Age (years) & $22.7 \pm 1.6$ & $31.3 \pm 9.1$ & $23.4 \pm 1.8$ \\
\hline $\begin{array}{l}\text { Height } \\
(\mathrm{cm})\end{array}$ & $165.0 \pm 6.2$ & $161.5 \pm 9.1$ & $171.2 \pm 6.2$ \\
\hline $\begin{array}{l}\text { Weight } \\
(\mathrm{kg})\end{array}$ & $82.0 \pm 14.3$ & $63.9 \pm 10.2$ & $63.0 \pm 4.8$ \\
\hline $\begin{array}{l}\text { Body fat } \\
(\%)\end{array}$ & $13.1 \pm 7.6$ & $23.0 \pm 6.4$ & $11.9 \pm 2.9$ \\
\hline $\begin{array}{l}V \mathrm{O}_{2 \max } \\
(\mathrm{L} / \min )\end{array}$ & $3.57 \pm 0.61$ & $2.04 \pm 0.26^{\mathrm{a}}$ & $3.50 \pm 0.40$ \\
\hline $\begin{array}{r}\mathrm{HR}_{\max } \\
(\mathrm{bpm}) \\
\end{array}$ & $199.0 \pm 7.0$ & $188.5 \pm 9.1^{\mathrm{a}}$ & $197.0 \pm 8.1$ \\
\hline $\begin{array}{l}\text { Resistance } \\
\text { training } \\
\text { equipment }\end{array}$ & $\begin{array}{c}\text { Universal resistance training } \\
\text { equipment }\end{array}$ & $\begin{array}{c}\text { Universal resistance training } \\
\text { equipment }\end{array}$ & Without any equipment \\
\hline Exercises & $\begin{array}{l}\text { Squat, bench press, Roman } \\
\text { chair sit-ups, one arm } \\
\text { dumbbell row, bent-arm } \\
\text { pullover, pull-ups, back } \\
\text { extension, and lat-pulldown }\end{array}$ & $\begin{array}{l}\text { Leg press, knee extension, } \\
\text { knee flexion, biceps curl, } \\
\text { triceps extension, bench press, } \\
\text { and back extension }\end{array}$ & $\begin{array}{l}\text { Squat, push-up, lunge, heel- } \\
\text { raise, hip-lift, and crunch }\end{array}$ \\
\hline $\begin{array}{l}\text { Intensity, } \\
\text { repetitions } \\
\text { and } \\
\text { recovery } \\
\text { duration }\end{array}$ & $\begin{array}{l}\text { Many repetitions as possible } \\
\text { (typically } 8-12 \text { reps) at } 60 \% \\
1 \mathrm{RM} \text { (except for sit-ups } 25 \\
\text { reps, pull-ups, and back } \\
\text { extension } 10 \text { reps) during } 45-\mathrm{s} \\
\text { exercise period, } 2 \text { sets, } 60-\mathrm{s} \\
\text { interval }\end{array}$ & $\begin{array}{l}15 \text { repetitions (or until failure), } \\
\text { at } 65 \% 1 \mathrm{RM}, 3 \text { sets, } 30-\mathrm{s} \\
\text { transition time, } 2 \text {-min recovery }\end{array}$ & $\begin{array}{l}10 \text { repetitions at body weight } \\
\text { with both the concentric and } \\
\text { eccentric phases were set to } 3 \mathrm{~s} \text {, } \\
3 \text { sets, } 30 \text {-s interval time } \\
\text { between exercises }\end{array}$ \\
\hline $\begin{array}{c}\text { Duration of } \\
\text { Ex (min) }\end{array}$ & 27 & Depends on subjects & 26.5 \\
\hline $\begin{array}{l}\text { Ex EE } \\
(\text { kcal })\end{array}$ & $\sim 240$ & $\sim 225$ & $\sim 100$ \\
\hline $\begin{array}{l}\% \dot{V} \mathrm{O}_{2 \max } \\
\text { of } \mathrm{RE}\end{array}$ & $\sim 44$ & $\sim 38$ & $\sim 22$ \\
\hline
\end{tabular}


Table III. Studies examining recovery oxygen consumption (ROC) for resistance training and treadmill locomotion with matched EE during Ex (Continued)

\begin{tabular}{|c|c|c|c|c|c|c|}
\hline Study & \multicolumn{2}{|c|}{ Burleson et al. (1998) } & \multicolumn{2}{|c|}{ Braun et al. (2005) } & \multicolumn{2}{|c|}{ Current study } \\
\hline Treadmill & \multicolumn{2}{|c|}{ Walking or jogging } & \multicolumn{2}{|c|}{ NR (unknown) } & \multicolumn{2}{|c|}{ Walking } \\
\hline $\begin{array}{l}\text { Response of } \\
\text { Ex }\end{array}$ & RE & Treadmill & $\mathrm{RE}$ & Treadmill & $\mathrm{RE}$ & Treadmill \\
\hline $\begin{array}{c}\dot{V} \mathrm{O}_{2} \\
(\mathrm{~L} / \mathrm{min})\end{array}$ & $1.58 \pm 0.08$ & $1.55 \pm 0.07$ & $0.76 \pm 0.02^{\mathrm{a}}$ & $0.74 \pm 0.02^{\mathrm{b}}$ & $0.71 \pm 0.12$ & $0.75 \pm 0.11$ \\
\hline HR (bpm) & $140 \pm 4 *$ & $110 \pm 3$ & $133 \pm 6^{*}$ & $98 \pm 5$ & $99 \pm 5^{*}$ & $87 \pm 11$ \\
\hline RER & $0.92 \pm 0.01 *$ & $0.77 \pm 0.01$ & $1.11 \pm 0.05^{*}$ & $0.88 \pm 0.05$ & $0.98 \pm 0.03 *$ & $0.84 \pm 0.02$ \\
\hline $\mathrm{La}(\mathrm{mM} / \mathrm{L})$ & $9.5 \pm 0.6^{*}$ & $0.8 \pm 0.2$ & \multicolumn{2}{|c|}{ NR } & $3.5 \pm 1.2^{*}$ & $0.9 \pm 0.2$ \\
\hline RPE & $12.8 \pm 0.3^{*}$ & $9.6 \pm 0.4$ & $14.3 \pm 0.2 *$ & $10.3 \pm 0.7$ & $13.5 \pm 2.3^{*}$ & $9.0 \pm 2.0$ \\
\hline $\begin{array}{l}\text { ROC } \\
\text { (L/30 min) }\end{array}$ & $19.0 \pm \mathrm{NR}^{*}$ & $12.7 \pm \mathrm{NR}$ & $8.0 \pm 0.3^{*}$ & $6.9 \pm 0.4$ & $8.7 \pm 0.9$ & $8.0 \pm 0.7$ \\
\hline $\begin{array}{l}\text { Diff. of } \\
\text { ROC }\end{array}$ & \multicolumn{2}{|c|}{$+58 \%$} & \multicolumn{2}{|c|}{$+15 \%$} & \multicolumn{2}{|c|}{$+8 \%$} \\
\hline
\end{tabular}

Diff. of ROC: difference of ROC for EE-matched RE and TW; NR: not reported.

${ }^{a}$ Estimated by $\dot{V} \mathrm{O}_{2 \max }$ and $\mathrm{HR}_{\max }$ from submaximal cardiorespiratory exercise test (85\% of age-estimated heart rate maximum) and age-estimated $\mathrm{HR}_{\max }$ using linear regression.

${ }^{\mathrm{b}}$ Obtained from figure.

*Significantly higher than TW Ex

With regard to ROC ( $0-30 \mathrm{~min}$ ), this study showed that the BWRE-slow session elicited 8\% as compared to TW. The absolute ROC in this study was lower than in previous studies. The RE protocols and the results of these and our current studies are summarized in Table III. The table shows that the magnitude of ROC depends on the intensity and/or the duration of RE.

As shown in Table II, there were no significant differences in RER in the two conditions during the total post-Ex ( $0-30 \mathrm{~min})$ period. However, the time course changes of RER during post-Ex were different in the two conditions. The RER decreased gradually and was lower for BWRE-slow 25-30 min post-Ex compared to TW with significant interaction of Ex mode $\times$ Time (Fig. 2B). Previous findings using high-load RE $(6,36)$ also reported that RER post-Ex was decreased by an acute RE, which was indicated by increased FAT oxidation during post-Ex. Braun et al. (8) investigated the time course of the RER post-Ex, and found that the RER was significantly higher at the start of recovery for RE, but the RER became significantly lower than the TW from about $30 \mathrm{~min}$ after Ex. These results are similar to the findings of this study.

A number of factors may have contributed to the decreased RER post-Ex. One possible factor in decreased RER during BWRE-slow is that BWRE-slow led to a reduction in glycogen storages. In general, as Ex intensity increases, the contribution of $\mathrm{CHO}$ as a fuel source increases during Ex (30) and the increased FAT oxidation during post-Ex may be due to sparing $\mathrm{CHO}$ and facilitating subsequent muscle glycogen restoration $(16,23)$. In this study, although the Ex EE of BWRE-slow was the same as that of TW, the La and RER of 
BWRE-slow was significantly higher than that of TW (Fig. 2B; Table II). It means that BWRE-slow is more dependent on the anaerobic glycolysis and decreases glycogen stores in skeletal muscle tissue, although the Ex intensity and duration were the same in BWRE-slow and walking Ex. These results indicated that BWRE-slow is a different Ex modality using different muscle groups and fiber types compared to normal walking Ex, although the same EE was consumed.

Performing BWRE-slow always induces muscle contraction. Tanimoto and Ishii (33) showed that low-intensity knee extension Ex with slow movement exhibited almost continuous muscular electric activity from the left vastus lateralis throughout the entire movement using electromyography (EMG) analyses. This suggests that the energy sources are continuously utilized during these kinds of Ex. Furthermore, low-intensity knee extension Ex with slow movement causes lowered muscle oxygenation level during Ex and post-Ex as compared to low intensity with normal speed using near-infrared spectroscopic (NIRS) analyses (33). Although we did not measure EMG nor NIRS in this study, previous studies suggest BWRE-slow make muscle tissue environment different from normal aerobic walking.

This study has several limitations. First, we only measured $V \mathrm{O}_{2}, V \mathrm{CO}_{2}, \mathrm{RER}$, and substrate oxidation using indirect calorimetry and La. RE may induce protein-related metabolism more than normal walking $(3,42)$, although this study did not assess protein-related EE. Second, the mouth-based RER obtained by indirect calorimetry does not fully reflect respiratory quotient (RQ) at muscle tissue level, because the $\mathrm{O}_{2}$ supply from mouth to tissue is fast, but the $\mathrm{CO}_{2}$ transfer from tissue to mouth has time delay (23). Thus, those results in RER exceeding RQ and can potentially lead to an overestimation and underestimation of substrate oxidation during Ex $(12,23)$. In addition, stability of the plasma bicarbonate buffering system affects the utilization of substrate oxidation $(22,23)$, but we did not assess it in this study. Furthermore, we measured ROC only 30 min after the Ex; thus, the long-term lasting influence (e.g., $24 \mathrm{~h}$ ) of BWRE-slow on ROC and substrate oxidations remains unclear. Previous studies have reported that differences in substrate oxidation during high-intensity and low-intensity Ex are compensated for during the post-Ex period $(24 \mathrm{~h})$ $(23,24,31)$. Finally, sample size of this study is small $(n=8)$ and limited to healthy young men. BWRE-slow was light- to moderate-intensity PA at least for healthy young men, but the intensity of BWRE-slow will become relatively higher intensity of Ex intensity for other populations. For example, BWRE-slow becomes $60 \% \mathrm{VO}_{2 \max }$ Ex for an older adult who has a $15-20 \mathrm{ml} \cdot \mathrm{kg}^{-1} \cdot \mathrm{min}^{-1} V \mathrm{O}_{2 \max }$ or five METs max capacity. The Ex practitioner or clinician should consider the individual's fitness level to prescribe RE programs, and the use of BWRE-slow, in the low fitness individuals or older adults ( $\geq 65$ year). It is important that additional research is required to carry out to investigate the long-term physiological responses in other population groups.

In conclusion, prior to this study, the EE of a full session of BWRE-slow had not been well examined. The EE observed in this study for BWRE-slow was $3.5 \pm 0.6 \mathrm{kcal} / \mathrm{min}$ and $3.1 \pm 0.3$ METs which is defined as moderate intensity in healthy young men (range: $2.7-3.7$ METs which varies low-to-moderate among individuals). This intensity is equivalent to normal walking with $\sim 4 \mathrm{~km} / \mathrm{h}$ speed. BWRE-slow is still glycolysis-dependent Ex modality compared to EE-matched walking, although the average intensity is much lower than in traditional RE. The RER became significantly lower than in normal walking for 25 min after Ex, which agrees with previous findings. FAT oxidation will be facilitated to compensate glycogen depletion in the utilized muscles of BWRE-slow at that stage. The BWRE-slow is 
an alternative Ex when people cannot perform walking outside or when machines or weights are not available, as well as a beneficial Ex to offer a variation for daily PA.

\section{Acknowledgements}

This work was supported in part by a collaborative research grant from the Juntendo University Graduate School of Health and Sports Science and Institute of Health and Sports Science \& Medicine. The authors would like to thank all subjects participating in this study. They would also like to thank J. E. Fink, PhD (Juntendo University) for critical reading and English editing.

\section{Conflict of interest}

None of the authors have any competing interests to disclose in this study.

\section{REFERENCES}

1. Ainsworth BE, Haskell WL, Herrmann SD, Meckes N, Bassett DR Jr, Tudor-Locke C, Greer JL, Vezina J, Whitt-Glover MC, Leon AS: 2011 compendium of physical activities: a second update of codes and MET values. Med. Sci. Sports Exerc. 43, 1575-1581 (2011)

2. American College of Sports Medicine: American College of Sports Medicine position stand. Progression models in resistance training for healthy adults. Med. Sci. Sports Exerc. 41, 687-708 (2009)

3. Ato S, Fujita S: Regulation of muscle protein metabolism by nutrition and exercise. J. Phys. Fit. Sports Med. 6, 119-124 (2017)

4. Ballor DL, Becque MD, Marks CR, Nau KL, Katch VL: Physiological responses to nine different exercise: rest protocols. Med. Sci. Sports Exerc. 21, 90-95 (1989)

5. Beckham SG, Earnest CP: Metabolic cost of free weight circuit weight training. J. Sports Med. Phys. Fitness 40, 118-125 (2000)

6. Binzen CA, Swan PD, Manore MM: Postexercise oxygen consumption and substrate use after resistance exercise in women. Med. Sci. Sports Exerc. 33, 932-938 (2001)

7. Bloomer RJ: Energy cost of moderate-duration resistance and aerobic exercise. J. Strength Cond. Res. 19, 878-882 (2005)

8. Braun WA, Hawthorne WE, Markofski MM: Acute EPOC response in women to circuit training and treadmill exercise of matched oxygen consumption. Eur. J. Appl. Physiol. 94, 500-504 (2005)

9. Brehm BA, Gutin B: Recovery energy expenditure for steady state exercise in runners and nonexercisers. Med. Sci. Sports Exerc. 18, 205-210 (1986)

10. Burd NA, West DW, Staples AW, Atherton PJ, Baker JM, Moore DR, Holwerda AM, Parise G, Rennie MJ, Baker SK, Phillips SM: Low-load high volume resistance exercise stimulates muscle protein synthesis more than high-load low volume resistance exercise in young men. PLoS One 5, e12033 (2010)

11. Burleson MA Jr, O’Bryant HS, Stone MH, Collins MA, Triplett-McBride T: Effect of weight training exercise and treadmill exercise on post-exercise oxygen consumption. Med. Sci. Sports Exerc. 30, 518-522 (1998)

12. Christmass MA, Dawson B, Passeretto P, Arthur PG: A comparison of skeletal muscle oxygenation and fuel use in sustained continuous and intermittent exercise. Eur. J. Appl. Physiol. Occup. Physiol. 80, 423-435 (1999)

13. Frayn KN: Calculation of substrate oxidation rates in vivo from gaseous exchange. J. Appl. Physiol. 55, 628-634 (1983)

14. Fujita E, Takeshima N, Kato Y, Koizumi D, Narita M, Nakamoto H, Rogers ME: Effects of body-weight squat training on muscular size, strength and balance ability in physically frail older adults. Int. J. Sport Health Sci. 14, 21-30 (2016)

15. Garber CE, Blissmer B, Deschenes MR, Franklin BA, Lamonte MJ, Lee IM, Nieman DC, Swain DP, American College of Sports Medicine: American College of Sports Medicine position stand. Quantity and quality of exercise for developing and maintaining cardiorespiratory, musculoskeletal, and neuromotor fitness in apparently healthy adults: guidance for prescribing exercise. Med. Sci. Sports Exerc. 43, 1334-1359 (2011)

16. Henderson GC, Fattor JA, Horning MA, Faghihnia N, Johnson ML, Mau TL, Luke-Zeitoun M, Brooks GA: Lipolysis and fatty acid metabolism in men and women during the postexercise recovery period. J. Physiol. 584, 963-981 (2007) 
17. Hirano M, Shindo M, Mishima S, Morimura K, Higuchi Y, Yamada Y, Higaki Y, Kiyonaga A: Effects of 2 weeks of low-intensity cycle training with different pedaling rates on the work rate at lactate threshold. Eur. J. Appl. Physiol. 115, 1005-1013 (2015)

18. Japan Sports Agency (2017): National Survey about implementation of sports and physical activity in 2016. Japan Sports Agency, Tokyo, pp. 10-58

19. Kamada M, Shiroma EJ, Buring JE, Miyachi M, Lee IM: Strength training and all-cause, cardiovascular disease, and cancer mortality in older women: a cohort study. J Am Heart Assoc. 6, e007677 (2017)

20. Knuttgen HG: Strength training and aerobic exercise: comparison and contrast. J. Strength Cond. Res. 21, 973-978 (2007)

21. Lagally KM, Cordero J, Good J, Brown DD, McCaw ST: Physiologic and metabolic responses to a continuous functional resistance exercise workout. J. Strength Cond. Res. 23, 373-379 (2009)

22. Luszczyk M, Flis DJ, Szadejko I, Laskowski R, Ziolkowski W: Excess post-exercise oxygen consumption and fat oxidation in recreationally trained men following exercise of equal energy expenditure: comparisons of spinning and constant endurance exercise. J. Sports Med. Phys. Fitness 58, 1781-1789 (2018)

23. Malatesta D, Werlen C, Bulfaro S, Cheneviere X, Borrani F: Effect of high-intensity interval exercise on lipid oxidation during postexercise recovery. Med. Sci. Sports Exerc. 41, 364-374 (2009)

24. Melanson EL, MacLean PS, Hill JO: Exercise improves fat metabolism in muscle but does not increase 24-h fat oxidation. Exerc. Sport Sci. Rev. 37, 93-101 (2009)

25. Mohamad NI, Cronin JB, Nosaka KK: Difference in kinematics and kinetics between high- and low-velocity resistance loading equated by volume: implications for hypertrophy training. J. Strength Cond. Res. 26, 269-275 (2012)

26. Morton RW, Oikawa SY, Wavell CG, Mazara N, McGlory C, Quadrilatero J, Baechler BL, Baker SK, Phillips SM: Neither load nor systemic hormones determine resistance training-mediated hypertrophy or strength gains in resistance-trained young men. J. Appl. Physiol. (1985) 121, 129-138 (2016)

27. Nakagata T, Naito H, Yamada Y: Metabolic equivalents of body weight resistance training with slow movement: implications for exercise prescription and health promotion. J. Exerc. Physiol. Online 21, 29-38 (2018)

28. Nakamoto H, Yoshitake Y, Takai Y, Kanehisa H, Kitamura T, Kawanishi M, Mori S: Knee extensor strength is associated with Mini-Mental State Examination scores in elderly men. Eur. J. Appl. Physiol. 112, 1945-1953 (2012)

29. Osterberg KL, Melby CL: Effect of acute resistance exercise on postexercise oxygen consumption and resting metabolic rate in young women. Int. J. Sport Nutr. Exerc. Metab. 10, 71-81 (2000)

30. Romijn JA, Coyle EF, Sidossis LS, Gastaldelli A, Horowitz JF, Endert E, Wolfe RR: Regulation of endogenous fat and carbohydrate metabolism in relation to exercise intensity and duration. Am. J. Physiol. 265, E380-E391 (1993)

31. Saris WH, Schrauwen P: Substrate oxidation differences between high- and low-intensity exercise are compensated over 24 hours in obese men. Int. J. Obes. Relat. Metab. Disord. 28, 759-765 (2004)

32. Schleppenbach LN, Ezer AB, Gronemus SA, Widenski KR, Braun SI, Janot JM: Speed- and circuit-based high-intensity interval training on recovery oxygen consumption. Int. J. Exerc. Sci. 10, 942-953 (2017)

33. Tanimoto M, Ishii N: Effects of low-intensity resistance exercise with slow movement and tonic force generation on muscular function in young men. J. Appl. Physiol. (1985) 100, 1150-1157 (2006)

34. Tanimoto M, Sanada K, Yamamoto K, Kawano H, Gando Y, Tabata I, Ishii N, Miyachi M: Effects of whole-body low-intensity resistance training with slow movement and tonic force generation on muscular size and strength in young men. J. Strength Cond. Res. 22, 1926-1938 (2008)

35. Taylor HL, Buskirk E, Henschel A: Maximal oxygen intake as an objective measure of cardio-respiratory performance. J. Appl. Physiol. 8, 73-80 (1955)

36. Thornton MK, Potteiger JA: Effects of resistance exercise bouts of different intensities but equal work on EPOC. Med. Sci. Sports Exerc. 34, 715-722 (2002)

37. Tsuzuku S, Kajioka T, Sakakibara H, Shimaoka K: Slow movement resistance training using body weight improves muscle mass in the elderly: a randomized controlled trial. Scand. J. Med. Sci. Sports. 28, 1339-1344 (2018)

38. US Department of Health and Human Services (2008): 2008 Physical Activity Guidelines for Americans. US Department of Health and Human Services, Washington, DC

39. Watanabe Y, Tanimoto M, Oba N, Sanada K, Miyachi M, Ishii N: Effect of resistance training using bodyweight in the elderly: comparison of resistance exercise movement between slow and normal speed movement. Geriatr. Gerontol. Int. 15, 1270-1277 (2015)

40. Weir JB: New methods for calculating metabolic rate with special reference to protein metabolism. J. Physiol. 109, 1-9 (1949) 
41. Wilmore JH, Parr RB, Ward P, Vodak PA, Barstow TJ, Pipes TV, Grimditch G, Leslie P: Energy cost of circuit weight training. Med. Sci. Sports 10, 75-78 (1978)

42. Wolfe RR: Skeletal muscle protein metabolism and resistance exercise. J. Nutr. 136, 525s-528s (2006)

43. World Health Organization (2010): Global recommendations on physical activity for health. World Health Organization, Geneva

44. Yamada Y, Nishizawa M, Uchiyama T, Kasahara Y, Shindo M, Miyachi M, Tanaka S: Developing and validating an age-independent equation using multi-frequency bioelectrical impedance analysis for estimation of appendicular skeletal muscle mass and establishing a cutoff for sarcopenia. Int. J. Environ. Res. Public Health 14, 809 (2017)

45. Yoshitake Y, Takai Y, Kitamura T, Kawanishi M, Kanehisa H: Body mass-based exercise in middle-aged and older women. Int. J. Sports Med. 32, 924-928 (2011) 